\title{
Revisão sobre a utilização da teoria das representações sociais nos estudos sobre homofobia no Brasil
}

\section{Review of the use of the theory of social representations in homophobia studies in Brazil}

\section{Revisión sobre la utilización de la teoría de las representaciones sociales en los estudios sobre la homofobia en Brasil}

\author{
Lawerton Braga da Silva* \\ Universidade Federal da Paraíba - UFPB, João Pessoa, Paraíba, Brasil
}

\author{
Renata Lira dos Santos Aléssio** \\ Universidade Federal de Pernambuco - UFPE, Recife, Pernambuco, Brasil
}

\begin{abstract}
RESUMO
Este artigo de revisão objetiva destacar as contribuições e fazer um panorama dos estudos que utilizam a teoria das representações sociais para estudar o fenômeno da homofobia no contexto da psicologia social brasileira. A pesquisa foi realizada nas bases BVS, PePSIC e SciELO, sem demarcação de tempo. Foram encontrados sete artigos empíricos realizados no contexto brasileiro, três de cunho quantitativo e quatro qualitativos. Cinco artigos deixaram claros os modelos escolhidos, entre eles a abordagem societal e abordagem estrutural. Também apontaram quatro núcleos temáticos que não são excludentes, mas dizem respeito ao foco de cada trabalho: (1) Expressão do preconceito e natureza da homossexualidade; (2) Adoção homoparental; (3) Representações sociais da homossexualidade; (4) Professores e representações sociais da homossexualidade e diversidade sexual. Duas tendências podem ser apontadas quanto aos objetivos: (1) a compreensão das expressões do preconceito (sutil e flagrante) com base nas representações sobre a natureza da homossexualidade; (2) as representações a respeito da homossexualidade. É preciso que os estudos futuros mudem seu foco, propondo formas de enfrentamento e combate a discriminação homofóbica, além de considerar o lugar de fala de LGBT. Deixando a busca pela origem da homofobia e da homossexualidade em segundo plano.
\end{abstract}

Palavras-chave: psicologia social, representações sociais, preconceito, homofobia e homossexualidade.

\section{ABSTRACT}

This review article aims to highlight the contributions and give an overview of the studies that use social representations theories to study the homophobia phenomenon in the context of Brazilian Social Psychology. The 
research was carried out in the BVS, PePSIC and SciELO bases, without time demarcation. seven empirical articles were found in the Brazilian context. Three with quantitative aproach and four with qualitative aproach. Five articles made clear their chosen models, among them the societal approach and structural approach. They also pointed out four thematic nuclei that were not excluding but related to the focus of each work: (1) Expressions of prejudice and nature of homosexuality; (2) Homoparental adoption; (3) Social representations of homosexuality and; (4) Teachers and social representations of homosexuality and sexual diversity. Two tendencies can be pointed toward the objectives: (1) the understanding of expressions of prejudice (subtle and flagrant) based on representations about the nature of homosexuality and; (2) representations regarding homosexuality. It is necessary that future studies change their focus, proposing strategies to face and fight homophobic discrimination, as well as taking into account the place of LGBT speech. Leaving the search for the origin of homophobia and homosexuality in the background.

Keywords: social psychology, social representations, prejudice, homophobia and homosexuality.

\section{RESUMEN}

Este artículo de revisión tiene por objetivo destacar las contribuciones y hacer un panorama de los estudios que utilizan la teoría de las representaciones sociales para estudiar el fenómeno de la homofobia en el contexto de la psicología social brasileña. La investigación se realizó en las bases BVS, PePSIC y SciELO, sin demarcación de tiempo. Se encontraron sete artículos empíricos realizados en el contexto brasileño. Tres de carácter cuantitativo y cuatro cualitativos. Cinco artículos dejaron claros los modelos escogidos, entre ellos el enfoque societal y el enfoque estructural. También señalaron cuatro temas que no son excluyentes entre sí, sino que se relacionan con el enfoque de cada trabajo: (1) la expresión de los prejuicios y la naturaleza de la homosexualidad; (2) Adopción homoparental; (3) Representaciones sociales de la homosexualidad; (4) Profesores y representaciones sociales de la homosexualidad y diversidad sexual. Dos tendencias se pueden identificar cuanto a los objetivos: (1) la comprensión de las expresiones del prejuicio (sutiles y evidentes) con base en las representaciones acerca de la naturaleza de la homosexualidad y; (2) las representaciones acerca de la homosexualidad. Es necesario que los estudios futuros cambien su enfoque, proponiendo formas de enfrentamiento y combate a la discriminación homofóbica, además de considerar el lugar de habla de LGBT. Dejando la búsqueda por el origen de la homofobia y de la homosexualidad en segundo plano.

Palabras-clave: Psicología Social, Representaciones Sociales, Prejuicio, Homofobia y Homosexualidad.

Houve um tempo em que a homossexualidade foi considerada doença. Somente em 1973, a American Psychiatric Association (APA) e, em 1990, a Organização Mundial da Saúde (OMS), removeram a homossexualidade da lista de doenças mentais. No Brasil, em 1999, o Conselho Federal de Psicologia se pronunciou oficialmente por meio da Resolução01/1999, não reconhecendo a homossexualidade como doença, distúrbio ou perversão, mas como uma das possibilidades de 
expressão da sexualidade, proibindo, inclusive, qualquer prática que tenha como objetivo "curar" os sujeitos homossexuais.

A homofobia, enquanto fenômeno social, já existia. Contudo, na literatura psicológica, 0 termo foi popularizado pelo psicólogo americano George Weinberg em 1972 com a publicação do livro "Society and the Healthy Homosexual", no qual define a homofobia como um"pânico de partilhar um mesmo espaço com homossexuais e no caso dos próprios homossexuais, a auto aversão" (Gato, Carneiro, \& Fontaine, 2011, p. 141). Na psicologia brasileira, o tema só passou a ser tratado enquanto objeto de estudo em $2000 \mathrm{com} o$ trabalho pioneiro de Camino e Pereira (2000), trata-se uma pesquisa sobre a atitude de professores e alunos de Psicologia de João Pessoa frente a Resolução01/1999 do CFP.

Apesar da relevância do tema, ainda existem poucas publicações em revistas científicas dedicadas a esse fenômeno. É importante evidenciar que, existem sim, diversos encontros, reuniões e congressos que discutem sobre o tema, além de diversas pesquisas que acontecem nas pós-graduações do país. Entretanto, as produções, não são publicadas e seu compartilhamento, restringemse aos anais de eventos.

Segundo Fleury e Torres (2007), em um levantamento feito na SciELO (Scientific Eletronic Library On-Line), no dia 30 de abril de 2006, usando a palavra-chave "preconceito contra homossexuais", apenas o trabalho de Lacerda, Pereira e Camino (2002) foi encontrado. Peroni (2011) realizou uma revisão sistemática com o objetivo de definir as especificidades das formas de apresentação da homofobia em nosso contexto e encontrou 22 artigos publicados entre 1996 e 2011. Pereira (2017) em uma revisão narrativa sobre homofobia e violência contra a população LGBT no Brasil encontrou 24 artigos. Rodrigues e Boeckel (2016) realizaram um trabalho de revisão sobre "Conjugalidade e homossexualidade: uma revisão sistemática de literatura" e encontraram sete trabalhos entre 2000 e 2015. Cecílio, Scorsolini-Comim e Santos (2013), em um artigo sobre a "Produção científica sobre adoção por casais homossexuais no contexto brasileiro", encontraram 10 artigos no período de 2000 a 2010. Pereira (2017) ao estudar a "Homossexualidade em cena: da naturalidade ao preconceito. Revisitando a produção científica nacional", encontrou 23 trabalhos publicados entre 2002 e 2015. Esses levantamentos mostram que os trabalhos ligados a homossexualidade e ao preconceito contra homossexuais, dentro da psicologia brasileira, ainda não se constituem como "um campo saturado".

Apesar do trabalho de Camino e Pereira (2000) ter sido pioneiro sobre o tema, o mesmo não se encontra disponível on-line. Dessa forma, uma segunda publicação, Lacerda et al. (2002), tem servido como base para diversos trabalhos até hoje, trata-se de um estudo 
no campo da Psicologia Social que utiliza da Teoria das Representações Sociais (TRS) como arcabouço teórico. Este pioneirismo acadêmico e escolha teórica despertaram o interesse por analisar como a homofobia tem sido estudada no campo da TRS. Santos et al. (2013), após a análise de 16 periódicos da área de Psicologia avaliados em 2012 pela CAPES com Qualis A1, A2 e B1 no período de 2007 a 2011, encontraram 3.501 artigos dos quais 550 foram classificados como artigos de Psicologia Social. Os resultados mostraram que $18 \%$ das publicações utilizaram a TRS como referencial teórico. Essas informações corroboram com o fato de a TRS ser, até hoje, um referencial presente nas pesquisas em Psicologia Social (Lima \& Techio, 2013).

Transformada em objeto de estudo, a homofobia passou ao longo do tempo por diferentes modificações quanto ao seu conceito e nomenclatura, sendo até hoje, objeto de debate (Costa \& Nardi, 2015; Junqueira, 2012). Expressões como homossexismo (Lehne, como citado em Logan, 1996), homonegativismo (Hudson \& Ricketts, 1980), heterossexismo (Morin, 1977), homopreconceito (Logan, 1996), preconceito sexual (Herek, 2000) e preconceito contra a diversidade sexual (Costa \& Nardi, 2015) podem ser encontrados na literatura. Contudo, a intenção aqui não é aprofundar a discussão sobre cada um deles. Nessa revisão, escolheu-se trabalhar com o termo "homofobia". Primeiro, por seguir uma tendência atual dos estudos sobre o preconceito contra homossexuais e, em segundo lugar, por ser uma expressão comumente utilizada nas relações sociais e nos meios de comunicação. Essa escolha, inclusive, está em consonância com a TRS, que se preocupa com o saber presente e produzido pelo senso comum, no qual todo sujeito desviante de uma lógica heteronormativa (a heterossexualidade como norma vigente da sociedade) é tido como homossexual (desviante da norma), incluindo assim, bissexuais, travestis, transexuais e transgêneros.

Borrillo (2009), para definir a homofobia, leva em consideração não somente o plano individual, mas considera os processos ideológicos. Para ele:

A homofobia pode ser definida como a hostilidade geral, psicológica e social àqueles ou àquelas que supostamente sentem desejo ou têm relações sexuais com indivíduos de seu próprio sexo. Forma particular de sexismo, a homofobia renega igualmente todos aqueles que não se enquadram nos papéis determinados para seu sexo biológico. Construção ideológica que consiste na promoção constante de uma forma (hetero) em detrimento de outra (homo), a homofobia organiza uma hierarquização das sexualidades, o que tem consequências políticas (Borrillo, 2009, p. 27). 
O autor chama a atenção para o fato de que a homofobia possui a mesma lógica excludente que outras formas de inferiorização, cujo objetivo é sempre desumanizar o outro. Ela "se constrói com base na atribuição de certas características ao grupo estigmatizado - entre elas, uma forte identidade -, na capacidade de mobilizar meios mais ou menos ocultos e na tendência a se apoiar em redes mais ou menos secretas" (Borrillo, 2009, p. 29). Ou seja, possui a característica de supervalorização de uns e o menosprezo de outros, como acontece, por exemplo, no racismo, no sexismo e na xenofobia. A homofobia está presente nas relações sociais e, principalmente, no senso comum, por meio de crenças, emoções e ideologias.

Jodelet (2001) define as representações sociais como uma modalidade de conhecimento prático, orientada para a comunicação e compreensão de uma realidade comum a um conjunto social. São formas de conhecimento que se manifestam como imagens, conceitos, categorias e teorias, mas não se reduzem apenas aos componentes cognitivos, pois são socialmente elaboradas e compartilhadas. De acordo com Jodelet (2016, p. 293) as representações sociais podem ser compreendidas "comme fondement d'unsystème de savoirs et de croyances; comme phénomènes qui se construisent et agissent socialement".

O conceito de representação social não está acabado ou esgotado, principalmente pela sua complexidade e polissemia. Moscovici (2009) apresenta-nos dois mecanismos essenciais que compõem as representações sociais: ancoragem e objetivação. A ancoragem é o processo pelo qual algo estranho e perturbador podem ser transformados através do nosso sistema de pensamentos préexistentes, comparando o que antes era desconhecido com algo conhecido e já categorizado em nossa mente, partilhado na memória social do grupo. "Ancorar é, pois, classificar e dar nome a alguma coisa" (Moscovici, 2009, p. 61). A objetivação "une a ideia de não familiaridade com a de realidade, torna-se a verdadeira essência da realidade. Percebida primeiramente como um universo puramente intelectual e remoto, a objetivação aparece então diante dos nossos olhos, física e acessível" (Moscovici, 2009, p. 71).

Além da articulação de elementos afetivos, mentais, da linguagem, da comunicação, cognição, entre outros, a perspectiva societal no estudo das representações, coloca as relações intergrupais no contexto dos conflitos culturais e ideológicos de uma sociedade, enfatizando e colocando em evidência explicações que destacam as relações de poder entre os grupos. Segundo Doise, o trabalho com as representações sociais fornece "o quadro mais estimulante para construir uma psicologia societal imbricando o estudo dos sistemas cognitivos no nível do indivíduo, no estudo dos sistemas relacionais e societais" (Doise, 2002, p. 30). 
De acordo com Abric, uma representação social é um "sistema de pré-codificação da realidade, pois ela determina um conjunto de antecipações e expectativas" (1994, p. 13) em relação a um objeto social. Desta forma, as representações selecionam informações, definem o que é tolerável, o que é lícito ou inadmissível numa dada situação. As finalidades de uma circunstância ou condição são explicadas de forma a torná-las consoantes às expectativas sociais do grupo. Trata-se de ativar um filtro - uma rede de ancoragens e de significações pré-existentes com a finalidade do controle da situação, para conferir um sentido - uma significação atribuída ao fenômeno em nível individual e social (Apostolidis, 2006).

Do ponto de vista do estudo dos processos representacionais, tratase de estudar o papel "dos fatores sociais na formação e no funcionamento do conhecimento de senso comum e de identificar os sistemas de interpretação e de pensamento coletivo", abandonando modelos do tipo do "pensador solitário" (Jodelet, 2005). Do ponto de vista do estudo dos conteúdos, trata-se de analisar como eles se desenvolvem socialmente, como se organizam "em termos de agenciamentos de significações e de trabalho sobre referências" (Vignaux \& Moscovici, 1994, p. 29).

A articulação entre conteúdos e processos mostra-se incontornável quando se procura compreender a dinâmica travada entre o sistema cognitivo e metasistema social (Apostolidis, 2006) na gênese das representações. Nesta perspectiva, as representações sociais podem ainda ser estudadas enquanto variável independente, uma pista teórico-metodológica a ser aprofundada. Trata-se de pôr em prática dispositivos de pesquisa capazes de levar em consideração esta dupla característica conceitual (processos/conteúdos).

As representações sociais estão na base do preconceito (Pereira, Torres, Pereira, \& Falcão, 2011; Lacerda et l., 2002), por isso a importância da inserção dessa teoria para a compreensão do fenômeno. Lacerda et al. (2002) definem o preconceito a partir da perspectiva societal como "uma forma de relação intergrupal onde, no quadro específico das relações de poder entre grupos, desenvolvem-se e expressam-se atitudes negativas e depreciativas além de comportamentos hostis e discriminatórios em relação aos membros de um grupo por pertencer a esse grupo" (p. 166).

Pereira, Dia, Lima e Souza (2017) mostram como as representações sociais sobre a natureza da homossexualidade partilhadas por pessoas heterossexuais podem estar na base da homofobia expressa nos ambientes de trabalho. As representações sociais desempenham uma função primordial no jogo das relações entre grupos (Gouveia, Camino, Ribeiro, \& Souza, 2016) podendo ser mediadoras de categorias identitárias (as representações são tomadas ao mesmo tempo enquanto processo e produto) ou ainda serem construídas a partir de processos identitários (assumindo o estatuto de produto). 
Essas relações levam a problematização do conceito de grupo social, aspecto que ultrapassa os objetivos desse artigo. Muito se tem produzido sobre representações sociais no contexto brasileiro (Jodelet, 2011), entretanto apesar de reconhecer a importância dos estudos sobre homofobia, não se encontrou revisões sobre esta literatura. Interroga-se aqui sobre a produção científica brasileira no campo das representações sociais que têm se debruçado sobre 0 fenômeno da homofobia.

\section{Método}

Trata-se de um estudo de revisão da literatura científica com o objetivo de descrever as contribuições teóricas e metodológicas que a Teoria das Representações Sociais proporcionou, até então, para o estudo da homofobia no contexto da Psicologia Social brasileira. Além disso, reunir e sintetizar os resultados de pesquisas sobre o tema de maneira sistemática e ordenada, a fim de destacar o estado da arte e apresentar possibilidades para futuros trabalhos.

Para a coleta de dados, foi realizada uma busca nas bases de dados BVS (Biblioteca Virtual em Saúde), PePsic (Periódicos Eletrônicos em Psicologia) e Scielo (Scientific Electronic Library Online). Optou-se por não delimitar um período específico, incluindo assim todos os trabalhos publicados até abril de 2017, quando a busca foi realizada.

Como descritores, foram utilizadas as palavras: "representações sociais", "homofobia", "preconceito contra homossexuais", "preconceito sexual" e "homossexualidade". As palavras foram inseridas em sua forma singular e, quando possível, plural. Além disso, foram realizadas combinações entre os termos, por exemplo: "representações sociais e homofobia", "representações sociais e preconceito contra homossexuais", entre outras possibilidades de combinação.

Os artigos que foram incluídos seguiram critérios específicos, são eles: (1) artigos indexados; (2) redigidos em português e no contexto brasileiro; (3) e com temática pertinente ao objetivo da revisão (homossexualidade). Os artigos excluídos foram aqueles que (1) possuíam apenas o resumo; (2) que não faziam parte dos periódicos de psicologia; (3) cujo idioma não era o português ou que estivesse fora do contexto brasileiro. Além desses, também foram descartadas as referências a livros, capítulos de livros, resenhas, cartas, notícias, anais de congresso, dissertações e teses.

A escolha por trabalhar com artigos indexados em bases de dados levou em consideração alguns critérios: o caráter técnico que o material possui; o processo de seleção até seu aceite final; o fato de as revistas possuírem corpo editorial aumentando o rigor dos trabalhos; revisores especializados nos assuntos específicos para 
qualificar e certificar que as publicações estão aptas para a publicação e; pelo fato da indexação permite a recuperação das informações de forma eficiente. $O$ Qualis dos periódicos não foi levado em consideração, já que se trata, unicamente, de uma classificação utilizada pelos programas de pós-graduação no Brasil e não uma base de dados indexadas.

Para facilitar a organização dos dados, o material foi dividido em eixos de análise, são eles: caracterização do tipo de estudo, objetivo, método e principais resultados encontrados. Os achados, também, foram categorizados em núcleos temáticos com o objetivo de mostrar a discussão realizada a respeito do tema.

\section{Resultados}

Foram encontrados 269 resumos de artigos no total (BVS: 175; Pepsic: 1; Scielo: 93), considerando a temática e os descritores escolhidos. Por meio dos critérios inclusão e exclusão escolhidos, a maior parte dos estudos foi excluída como mostra a Figura 1.

Figura 1 - Quantidade de Artigos encontrados nas bases de dados pesquisadas e fluxograma para chegarse à amostra do estudo.

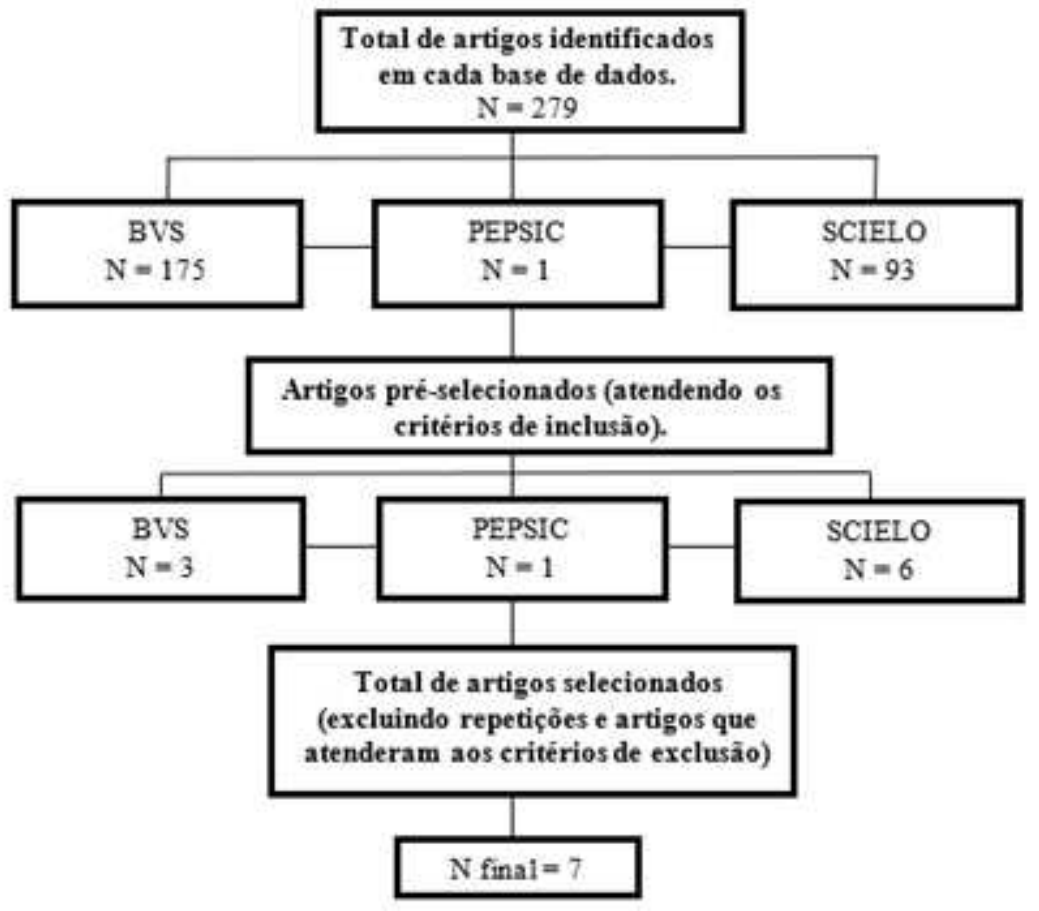

A revisão, constituiu-se então, de sete artigos científicos publicados entre 2002 e 2015, produzidos no contexto brasileiro e indexados em revistas de psicologia como observa-se Tabela 1 . Três dos estudos colocam apenas a TRS em seu título, mas não explicitam aspectos ligados ao preconceito (Scardua \& Souza, 2006; C. R. Pereira, Torres, 
Falcão, Pereira, 2013; Neves et al., 2015). Dois trabalhos trazem em seu título referência ao preconceito e a TRS (Lacerda et al., 2002; Pereira, 2011), um dos trabalhos não traz em seu título a teoria utilizada no estudo (Araújo, Oliveira, Sousa, \& Castanha, 2007). Já o trabalho de Souza, Silva e Santos (2015) é o único que utiliza o termo homofobia em seu título. Todos os estudos foram desenvolvidos no ambiente educacional, seja no contexto universitário ou nas redes de educação básica.

Tabela 1

Artigos Encontrados em Termos de Títulos, Autoria, Ano e Periódico Científico $(n=7)$

\begin{tabular}{|c|c|c|c|c|}
\hline No & $\begin{array}{l}\text { Título do artigo } \\
\end{array}$ & Autores & Ano & Revista \\
\hline 1 & $\begin{array}{l}\text { Um estudo sobre as formas de } \\
\text { preconceito contra homossexuais na } \\
\text { perspectiva das representações sociais }\end{array}$ & $\begin{array}{l}\text { Lacerda, } \\
\text { Pereira e } \\
\text { Camino }\end{array}$ & 2002 & $\begin{array}{l}\text { Psicologia: } \\
\text { Reflexão e } \\
\text { Crítica }\end{array}$ \\
\hline 2 & $\begin{array}{l}\text { O debate sobre a homossexualidade } \\
\text { mediada por representações sociais: } \\
\text { perspectiva homossexuais e } \\
\text { heterossexuais }\end{array}$ & $\begin{array}{l}\text { Scardua e } \\
\text { Filho }\end{array}$ & 2006 & $\begin{array}{l}\text { Psicologia: } \\
\text { Reflexão e } \\
\text { Crítica }\end{array}$ \\
\hline 3 & $\begin{array}{l}\text { Adoção de crianças por casais } \\
\text { homoafetivos: um estudo comparativo } \\
\text { entre universitários de direito e } \\
\text { psicologia }\end{array}$ & $\begin{array}{l}\text { Araújo et } \\
\text { al. }\end{array}$ & 2007 & $\begin{array}{l}\text { Psicologia e } \\
\text { Sociedade }\end{array}$ \\
\hline 4 & $\begin{array}{l}\text { Preconceito contra homossexuais e } \\
\text { representações sociais da } \\
\text { homossexualidade em seminaristas } \\
\text { católicos e evangélicos }\end{array}$ & $\begin{array}{l}\text { Pereira et } \\
\text { al. }\end{array}$ & 2011 & $\begin{array}{l}\text { Psicologia: } \\
\text { Teoria e } \\
\text { Pesquisa }\end{array}$ \\
\hline 5 & $\begin{array}{l}\text { O papel das representações sociais } \\
\text { sobre a natureza da } \\
\text { homossexualidade na oposição ao } \\
\text { casamento civil e à adoção por } \\
\text { famílias homoafetivas }\end{array}$ & $\begin{array}{l}\text { Pereira et } \\
\text { al. }\end{array}$ & 2013 & $\begin{array}{l}\text { Psicologia: } \\
\text { Teoria e } \\
\text { Pesquisa }\end{array}$ \\
\hline 6 & $\begin{array}{l}\text { Homofobia na escola: as } \\
\text { representações de educadores/as }\end{array}$ & $\begin{array}{l}\text { Souza, } \\
\text { Silva e } \\
\text { Santos }\end{array}$ & 2015 & $\begin{array}{l}\text { Temas em } \\
\text { Psicologia }\end{array}$ \\
\hline 7 & $\begin{array}{l}\text { Representações sociais de professores } \\
\text { sobre a diversidade sexual em uma } \\
\text { escola paraense }\end{array}$ & $\begin{array}{l}\text { Neves et } \\
\text { al. }\end{array}$ & 2015 & $\begin{array}{l}\text { Psicologia } \\
\text { Escolar e } \\
\text { Educacional }\end{array}$ \\
\hline
\end{tabular}

Todos os artigos são empíricos e os participantes são formados por estudantes universitários dos cursos de psicologia, medicina, serviço social e direito e, também, por seminaristas católicos e evangélicos (Ver Tabela 2). Em dois dos trabalhos, a amostra foi composta por professores (Souza, Silva, \& Santos, 2015; Neves et al., 2015). A amostragem aparece coerente ao caráter metodológico escolhido pelos autores dos estudos, utilizando-se de instrumentos padronizados para a coleta de dados para grandes contingentes de 
sujeitos, como questionários estruturados e escalas que posteriormente servem para a análise estatística dos dados, no caso de estudos quantitativos, como para os estudos com poucos sujeitos que utilizaram critérios específicos e rigorosos das pesquisas qualitativas.

Entre os artigos selecionados, três deles (Lacerda et al., 2002; Pereira et al., 2011; Pereira et al., 2013) investigaram o preconceito como objeto, sendo as representações sociais variáveis independentes, responsáveis por modificar os resultados encontrados. Nas outras quatro pesquisas, as representações sociais aparecem como variáveis dependentes. Elas são investigadas enquanto produtos e construídas no interior de determinados grupos sociais. Os trabalhos analisaram, por exemplo, questões referentes à diversidade sexual (Scardua \& Souza, 2006), a adoção (Araújo et al., 2007) e, as representações dos professores sobre determinados temas (Neves et al., 2015; Souza et al. 2015). 
Tabela 2

Método - Tipos de Estudo, Participantes e Principais Objetivos $(n=7)$

\begin{tabular}{|c|c|c|c|}
\hline$N^{\circ}$ & $\begin{array}{l}\text { Tipo de } \\
\text { estudo }\end{array}$ & Participantes & Principais Objetivos \\
\hline 1 & Empírico & $\begin{array}{l}220 \text { estudantes } \\
\text { universitários }\end{array}$ & $\begin{array}{l}\text { Analisar como a expressão do } \\
\text { preconceito ancora-se nas explicações } \\
\text { dadas à homossexualidade, no tipo de } \\
\text { curso, no sexo e na pertença religiosa } \\
\text { dos estudantes. }\end{array}$ \\
\hline 2 & Empírico & $\begin{array}{l}350 \text { estudantes } \\
\text { universitários }\end{array}$ & $\begin{array}{l}\text { Estudar as representações sociais da } \\
\text { homossexualidade entre estudantes } \\
\text { universitários, segundo orientação sexual } \\
\text { e sexo. }\end{array}$ \\
\hline 3 & Empírico & $\begin{array}{l}104 \text { estudantes } \\
\text { universitários }\end{array}$ & $\begin{array}{l}\text { Analisar e comparar as representações } \\
\text { sociais de estudantes em fase final do } \\
\text { curso de psicologia e de direito acerca da } \\
\text { adoção de crianças por casais } \\
\text { homossexuais. }\end{array}$ \\
\hline 4 & Empírico & $\begin{array}{c}374 \text { estudantes de } \\
\text { teologia }\end{array}$ & $\begin{array}{l}\text { Analisar as relações entre preconceito } \\
\text { contra homossexuais e as representações } \\
\text { sobre a homossexualidade em } \\
\text { seminaristas católicos e evangélicos. }\end{array}$ \\
\hline 5 & Empírico & $\begin{array}{l}297 \text { estudantes } \\
\text { universitários }\end{array}$ & $\begin{array}{l}\text { Analisar as relações entre preconceito, } \\
\text { apoio a políticas discriminatórias contra } \\
\text { homossexuais e representações sociais } \\
\text { sobre a natureza da homossexualidade. }\end{array}$ \\
\hline 6 & Empírico & $\begin{array}{c}7 \text { professores do } \\
\text { ensino } \\
\text { fundamental }\end{array}$ & $\begin{array}{l}\text { Analisar as representações sociais de } \\
\text { educadores/as da educação básica } \\
\text { (ensino fundamental maior) acerca da } \\
\text { homofobia e compreender quais os } \\
\text { principais conteúdos das representações } \\
\text { que eles possuem acerca da homofobia, } \\
\text { bem como compreender como seus } \\
\text { conhecimentos e vivências ancoram a } \\
\text { homofobia na escola. }\end{array}$ \\
\hline 7 & Empírico & $\begin{array}{l}50 \text { professores de } \\
\text { ensino médio }\end{array}$ & $\begin{array}{l}\text { Identificar e analisar a estrutura das } \\
\text { representações sociais de professores } \\
\text { sobre diversidade sexual considerando-se } \\
\text { a teoria do núcleo central. }\end{array}$ \\
\hline
\end{tabular}

Em relação à abordagem metodológica (ver Tabela 3), três trabalhos tiveram o enfoque em métodos quantitativos (Lacerda et al., 2002; Pereira et al., 2011; Pereira et al., 2013). A análise do preconceito primou pela utilização de questionários e escalas cujos participantes responderam sobre situações do cotidiano (escala de rejeição à intimidade) e avaliações relacionadas às emoções para comum homossexual (escala de expressão emocional). Os estudos qualitativos (Araújo et al., 2007; Neves et al., 2015; Scardua \& 
Souza, 2006; Souza et al. 2015) utilizaram roteiros que auxiliaram nas entrevistas, tanto semiestruturadas como de associação livre.

Os principais resultados foram agrupados em quatro núcleos temáticos, a saber: (1) expressão do preconceito e natureza da homossexualidade; (2) adoção homoparental; (3) representações sociais da homossexualidade; (4) professores e representações sociais da homossexualidade e diversidade sexual. Esses núcleos não se excluem, mas se complementam, tendo em vista que os temas citados aparecem de alguma forma nos diferentes estudos. A classificação aqui realizada, diz respeito ao foco de cada pesquisa.

Tabela 3

Métodos e Principais Resultados Encontrados nos Estudos Revisados $(n=7)$

\begin{tabular}{|c|c|}
\hline No & Método \\
\hline 1 & 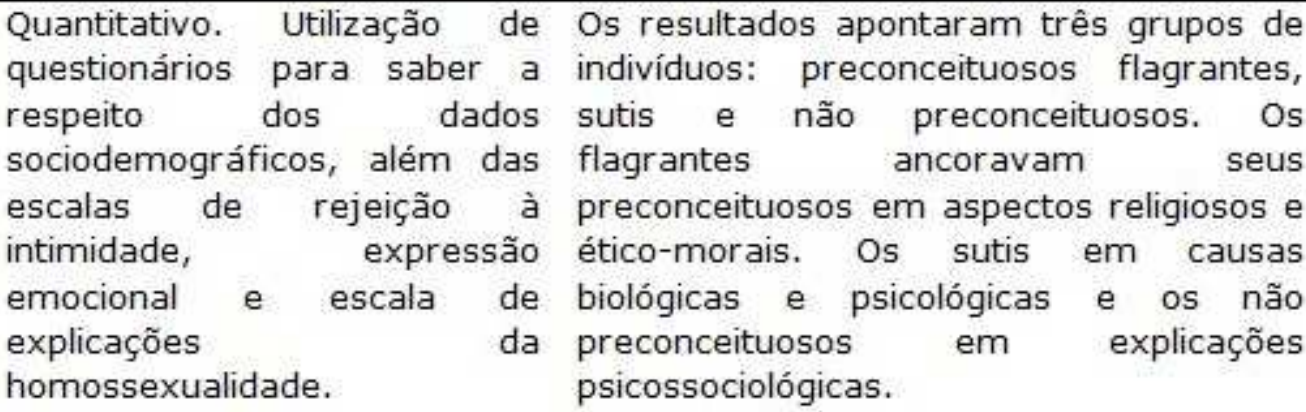 \\
\hline
\end{tabular}

2 Qualitativo. Aplicação de um questionário com uma questão de associação livre a respeito da homossexualidade e suas possíveis causas. As informações foram analisadas através da análise de conteúdo temática de Bardin (1977).

Percebeu-se diferenças significativas entre os grupos. Enquanto os homens homossexuais, procuravam justificar e legitimar publicamente

homossexualidade com diferentes argumentos, as mulheres homossexuais preferiram deixar suas questões num plano interpessoal (familia, namoro) para obter reconhecimento social. Já os homens e mulheres heterossexuais, a respeito da normatização e conteúdo que reforçam as convenções sociais, indicaram menos possibilidades de reconhecimento da homossexualidade

3 Qualitativo. Usou-se um questionário dividido em duas partes: a primeira sobre aspectos sociodemográficos; e a segunda composta de uma pergunta: Qual a sua opinião sobre a adoção de crianças por casais homossexuais?

Percebeu-se posicionamentos contrários acerca da adoção por casais homoafetivos. Preocupações quanto a influência da orientação dos pais para as crianças e ausência de referencial paterno ou materno, além da crença de que essas crianças poderiam desenvolver distúrbios psicológicos ou problemas morais. 
Quantitativo. Aplicação individual de questionários e duas escalas para medir o preconceito. Uma de rejeição à relação de proximidade e outra para medir a expressão de emoções. Medida de crenças acerca da homossexualidade.

Quantitativo. Aplicou-se um questionário que além de conter indicadores sociodemográficos, continham uma medida de crenças sobre a natureza da homossexualidade, uma medida de preconceito contra homossexuais, uma medida de oposição à adoção de crianças por casais homoafetivos e uma medida de oposição ao casamento entre pessoas do mesmo sexo.

Qualitativo. Foi elaborado um questionário para auxiliar na entrevista semiestruturada e empregou-se a análise de conteúdo categorial temática de Bardin (1977) para analisar as informações.

7 Qualitativo. Utilizou-se a técnica de evocação ou associação livre de palavras, por meio de um formulário que foi preenchido após a produção de cinco palavras ou expressões. As análises foram feitas pelo software EVOC2003.
Os resultados indicaram duas formas de preconceito: sutil e flagrante. 0 sutil relacionado com as crenças em uma natureza biológica e psicossocial e o flagrante em uma representação éticomoral.

$\begin{array}{lr}\text { Os resultados mostraram que as } \\ \text { representações } & \text { sobre }\end{array}$ homossexualidade baseadas em crenças religiosas, moralistas e psicológicas predizem o maior apoio às políticas discriminatórias contra os homossexuais. A crença na natureza cultural da homossexualidade prediz o menor apoio a essas políticas.

Os resultados revelaram que as representações dos/as docentes acerca da homofobia englobam uma variedade de pensamentos, crenças, ideias préestabelecidas e contradições. Pois, continham concepções reducionistas a respeito da homofobia, além de perceber práticas sutis do preconceito.

Os dados indicaram a existência de dois grupos de professores em condições diferentes, os que já são mais tolerantes quanto à diversidade sexual e os que não são tolerantes.

\section{Expressão do preconceito e natureza da homossexualidade}

Entre os sete artigos que foram selecionados, três (Lacerda et al., 2002; Pereira et al., 2011; Pereira et al., 2013) tiveram como um de 
seus objetivos investigar como estudantes universitários e seminaristas católicos e evangélicos expressam seu preconceito contra os homossexuais (sutil, flagrante ou não preconceituoso). Utilizaram a TRS como ferramenta de análise para explicar como as diferentes expressões do preconceito estão ancoradas nas explicações dadas à homossexualidade.

No estudo de Lacerda et al. (2002), os autores introduziram uma análise das explicações da homossexualidade no preconceito contra homossexuais por meio de uma escala que continha um conjunto de cinco itens com possíveis causas, a saber: biológica, psicológica, psicossocial, religiosa e ético-moral. Além disso, averiguaram o preconceito a partir de duas dimensões: a rejeição à intimidade e à expressão de emoções positivas e negativas. No estudo, foi possível traçar um perfil dos participantes no que se refere às explicações da homossexualidade e classificá-los em preconceituosos sutis, preconceituosos flagrantes e não preconceituosos.

Pereira et al. (2011) por meio de um estudo correlacional com seminarista evangélicos e católicos, analisou como esses sujeitos expressam o preconceito contra os homossexuais, além de identificar quais as concepções a respeito da natureza da homossexualidade que esses dois grupos possuíam. Dois grupos foram identificados, sutis e flagrantes, diferente do estudo anteriormente citado (Lacerda et al., 2002) que identificou o grupo de indivíduos não preconceituosos.

Em um outro contexto, Pereira et al. (2013) pôde analisar como o preconceito está relacionado ao apoio às políticas discriminatórias contra homossexuais na oposição ao casamento civil, adoção por famílias homoafetivas e as relações entre as crenças sobre a homossexualidade e a discriminação. Semelhante aos estudos de Lacerda et al. (2002) e Pereira et al. (2011), foi possível perceber que as crenças ligadas a natureza da homossexualidade aos conceitos religiosos, ético-morais e psicológicos, formavam a base de argumento das pessoas que eram contra a adoção de crianças por casais homoafetivos, colocando-os na posição de preconceituosos flagrantes.

\section{Adoção homoparental}

Nessa revisão, o tema da adoção apareceu em dois trabalhos (Araújo et al., 2007; Pereira et al., 2013). Contudo, no trabalho de Pereira et al. (2013), a questão da adoção não foi o objetivo dos autores. Ela apareceu, na verdade, em uma escala de oposição a adoção de crianças por homossexuais. Especificamente, a adoção, assim como o casamento dizem respeito a políticas discriminatórias que estão ancorados nas representações sociais. 
Araújo et al. (2007) tiveram como objetivo, analisar as representações sociais de 104 estudantes universitários em fase final dos cursos de psicologia e direito a respeito da adoção por casais homossexuais. Os autores chegaram à conclusão de que $51 \%$ dos estudantes, de ambos os cursos, são contrários a adoção. Desses, apenas $29 \%$ do curso de direito e $40 \%$ do curso de psicologia são favoráveis. Muitos, justificaram suas posições por acreditarem que essa prática fere o princípio natural da vida. Segundo os autores, essa posição contrária, diz respeito às concepções que os estudantes têm a respeito do homossexual e da homossexualidade, como sendo uma doença, um crime e um pecado.

Poucos estudantes ( $16 \%$ direito e $10 \%$ psicologia) perceberam a adoção como uma atitude inclusiva. As consequências que a adoção homoparental acarretariam, estão ancoradas em explicações ligadas a natureza da homossexualidade, como exposto no trabalho de Lacerda et al. (2002). Os estudantes acreditam que a adoção traria diversos problemas para a criança, por exemplo, elas seriam vítimas de preconceito, não teriam um referencial paterno/materno, a orientação dos pais influenciaria a dos filhos, além de problemas de ordem moral e distúrbios psicológicos.

A respeito da adoção, os artigos evidenciaram o papel que as representações sociais possuem no preconceito e discriminação de homossexuais, estando na base das atitudes e dos comportamentos dos atores sociais, modificando e justificando essas atitudes e comportamentos. Além disso, os autores mostraram como as crenças a respeito da natureza da homossexualidade representam um fator preponderante na determinação do preconceito e discriminação.

\section{Representações sociais da homossexualidade}

Entre os sete artigos encontrados, apenas um (Scardua \& Souza, 2006) teve como objetivo principal compreender as representações sociais da homossexualidade. Os autores destacaram quatro aspectos encontrados: (1) causalidade; relacionado com a intenção e não intenção de ser/viver homossexual. Por exemplo, os heterossexuais acreditam que ser homossexual é uma escolha; (2) reconhecimento social, ligado às questões do âmbito pessoal ao público, como a visibilidade na sociedade e a legitimação da própria sexualidade; (3) a normatização, especificamente a norma como uma forma de controle e regulação de sexualidades não heteronormativas; (4) discriminação e preconceito, relacionado ao sofrimento e as desigualdades sociais.

A concepção que os participantes da pesquisa possuíam sobre a homossexualidade e sobre o homossexual correlacionam-se às desenvolvidas por Lacerda et al. (2002). Para estudantes 
heterossexuais, a homossexualidade é algo intencional ou fruto de uma frustração vivida pelos homossexuais. Já para os estudantes homossexuais, não existe uma intencionalidade ou causa específica. A concepção que os grupos heterossexuais possuem sobre 0 homossexual estão ligadas a um sujeito desviante que, por escolha pessoal, resolveu ser o que é. São pessoas anormais, sem moral ou com algum problema psicológico.

\section{Professores e representações sociais da homossexualidade e diversidade sexual}

Todos os trabalhos analisados foram desenvolvidos no contexto educacional (escolas e universidades). Entretanto, em dois deles, 0 público alvo não foram os alunos, mas os professores. Como objetivo, esses trabalhos investigaram as representações sociais que os professores possuíam acerca da diversidade sexual e da homofobia. No trabalho de Souza et al. (2015), foi possível encontrar uma variedade de pensamentos, crenças e ideias muitas vezes contraditórias a respeito da homofobia. Segundo os autores, alguns professores compreendiam a homofobia de forma reducionista, como sendo uma mera aversão aos homossexuais e o desconhecimento sobre 0 assunto ocasionou em representações precipitadas e arbitrárias, evidenciando, na maioria das vezes, expressões sutis do preconceito. O uso de termos como "homossexualismo", "condição" e "opção sexual" foi recorrente, além deles, representações ancoradas em determinadas normatizações sociais que, não questionadas, resultam e fomentam preconceito e discriminação. Em contraponto, ao serem questionados se a homofobia deveria ser considerada um crime, todos concordaram com sua criminalização.

Neves et al. (2015), em um estudo sobre as representações sociais de professores sobre a diversidade sexual em uma escola paraense, perceberam dois grupos de professores. Os tolerantes e os não tolerantes quanto a diversidade sexual. O primeiro grupo de professores, segundo os próprios autores, apresentaram ideias engessadas, estereotipadas e preconceituosas sobre o tema. Evocaram, por exemplo, termos como "opção sexual" e "homossexualismo". Definir a sexualidade como uma opção do sujeito é algo que também aparece nos estudos anteriores. Um fato que chama atenção é a utilização do sufixo "ismo", termo já em desuso por relacionar a homossexualidade como uma doença. O segundo grupo de professores, apresentou o "respeito ao outro" mesmo sem subsídios que fundamentassem essa representação. Segundo os autores, esse grupo estaria numa condição cuja tolerância à diversidade estaria sendo construída. 
O núcleo central das representações está ligado a liberdade e ao respeito e é possível que essas evocações tenham se sobressaído por fazerem parte de um consenso entre os professores. Outro fato apresentado é o de que muitos professores se autodeclaravam neutros quanto ao assunto. Nos sistemas periféricos, são encontrados posicionamentos contrários, justamente relacionados às concepções preconceituosas e/ou estereotipadas. Por fim, e não menos importante, os autores percebem uma urgência na ampliação do olhar do professor para que a sexualidade seja vista em sua plenitude.

Apesar dos trabalhos dessa revisão pertencerem ao contexto educacional, seja pela composição da amostra (universitários e professores) ou enquanto objeto e local de pesquisa (a escola e os docentes), uma distinção precisa ser pontuada em relação aos outros trabalhos. Souza et al. (2015) e Neves et al. (2015) ao abordarem as representações de docentes sobre a homofobia, colocam em pauta uma das principais ferramentas utilizadas e propostas para o combate ao preconceito e a discriminação, a educação. Em 2004, por exemplo, é lançado o programa "Brasil sem homofobia: programa de combate à violência e à discriminação contra GLTB (Gays, Lésbicas, Transgêneros, Bissexuais) e de promoção da cidadania de homossexuais". Nesse período começou uma tentativa de inserir o debate sobre homofobia, seus efeitos e suas relações com outros tipos de preconceito e discriminação. Cartilhas e livros com o objetivo de apresentar o panorama sobre o tema buscavam, sobretudo, contribuir na formação de professores, para que esses lidassem com as diferenças existentes nas escolas (Junqueira, 2009). Infelizmente essa iniciativa não teve continuidade, e os ataques de uma parcela conservadora resultaram em retrocessos para a educação brasileira.

Falar em combate e erradicação do preconceito não é uma tarefa fácil. Primeiro, a manutenção dos preconceitos interessa diferente setores, políticos, culturais e econômicos (Lima, 2013). Einstein dizia: "Vivemos num mundo em que é mais fácil quebrar um átomo do que um preconceito". Contudo, segundo Lima (2013), o preconceito pode sim, ser alterado e mesmo vencido, na pior das hipóteses não estar ligado à discriminação. Uma hipótese nossa é de que a modificação da expressão flagrante para sutil pode ser considerada como uma mudança nesse processo, afinal a internalização de uma norma antipreconceito faz, em certa medida, o sujeito pensar e refletir sobre sua, atitude, posicionamento e comportamento.

\section{Discussão}

Por meio dos núcleos temáticos, se observou duas tendências em relação aos objetivos dos artigos aqui descritos, são eles: (1) 
compreender as expressões do preconceito (sutil e flagrante) com base nas representações sobre a natureza da homossexualidade (representações sociais como processo e produto); (2) uma segunda, que busca investigar as representações a respeito da homossexualidade, ou seja, estudar as representações sociais enquanto produto.

Esses eixos servem como indicadores e pontos de reflexão. Em primeiro lugar questiona-nos quanto à forma que os pesquisadores utilizam a teoria, cujo interesse continua na gênese da homossexualidade e na mensuração do preconceito por meio de escalas. Em segundo lugar, revela aspectos que não estão sendo contemplados, como o enfrentamento do preconceito e o combate a práticas discriminatórias. O questionamento levantado por Saco, Couto e Koller (2016), ao falarem sobre uma "Psicologia branca" nos estudos sobre o preconceito racial no Brasil, serve-nos também como questionamento para esse trabalho. Somente o trabalho de Scardua e Souza (2006) possuía uma população declaradamente homossexual como participante ou cuja opinião foi considerada. Mais importante que descobrir o porquê de as pessoas nascerem homofóbicas ou o nível de seu preconceito é propor formas e estratégias de enfrentamento para que a homofobia institucional, aquela que leva a práticas discriminatórias em ambientes de trabalho e omissões do poder público na criação de políticas públicas, por exemplo, venha a ser solucionada.

Ainda com base na revisão de Sacco, Couto e Koller (2016). Essa revisão, também evidencia o fato de que os estudos sobre homofobia utilizam as mesmas populações (estudantes universitários e, em um deles, seminaristas). Somente dois estudos, contaram com a participação de professores do ensino básico e médio. Não existem estudos com outra parcela da população, sejam crianças, idosos, sindicalistas, etc.

Apesar de utilizarem a TRS, dois artigos não deixam clara a abordagem adotada (Araújo et al., 2007; Souza et al., 2015). Cinco estudos descreveram o modelo adotado, que foram Lacerda et al. (2002); Pereira et al. (2011); Pereira et al. (2013), com o modelo de análise quantitativa de Doise (abordagem societal) e o estudo de Scardua e Souza (2006) e Neves et al. (2015) com a abordagem estrutural (embora, no estudo de Scardua \& Souza, 2006, os autores não recorreram às análises estruturais de estudo da organização dos conteúdos em termos de núcleo central e sistema periférico).

Os artigos que utilizaram a abordagem societal consideraram que representações sociais e crenças podem ser conceitos análogos. Partem do pressuposto que cada explicação para a natureza da homossexualidade, as apresentadas nas escalas aplicadas, correspondem a uma representação social da homossexualidade. Esses estudos contribuem para aprofundamento das reflexões acerca 
do efeito de filtragem (Apostolidis, 2006) e antecipação (Abric, 1994) que as representações podem desempenhar na leitura do mundo social, entretanto, essa correspondência mereceria ser melhor problematizada, pois as representações sociais da homossexualidade podem conter elementos ancorados ao mesmo tempo em explicações biológicas, psicológicas e culturais.

Nos estudos, a coleta de dados foi provocada pelos pesquisadores, seja na aplicação das escalas, dos questionários ou das entrevistas. Os estudos em representações sociais não se debruçaram sobre o desenrolar espontâneo de discussões sobre homofobia, por exemplo, nas mídias impressas e digitais, nas análises documentais e de imagens. Essa alternativa é uma possibilidade futura, inscrevendo-se em uma tradição de pesquisa qualitativa que busca observar 0 fenômeno representacional de forma naturalística (Jodelet, 2005).

Outro aspecto que merece destaque é a utilização das representações sociais enquanto funções justificadoras de determinadas tomadas de posições e comportamentos. Reis e Bellini (2011), a esse respeito dizem que tais funções preservam e justificam a diferenciação social, estereotipando a relação entre os grupos, além de contribuírem para a discriminação ou manutenção do distanciamento entre eles. Isso acontece porque as representações sociais são utilizadas como guias de condutas para sujeitos e grupos se posicionarem diante de determinado objeto. Os grupos religiosos, por exemplo, utilizam o discurso de pecado e abominação para justificar seus posicionamentos contrários a qualquer assunto ligado a homossexualidade, entre eles a homofobia.

As representações sociais estão na base da homofobia, representando uma ferramenta de análise para a compreensão das expressões do preconceito e, porque não, como estratégia de combate ao mesmo. A crença de que a homossexualidade é mais uma orientação sexual (crença psicossocial), por exemplo, precisa ser difundida através de uma educação que é política e pautada em um projeto de sociedade com papel central tanto nas políticas públicas, quanto nas relações humanas e sociais. Essa, ainda, continua sendo umas das principais estratégias apresentadas para que antigas crenças sejam superadas e reformuladas.

\section{Conclusão}

As questões ligadas à homofobia não se esgotaram, continuam sendo pertinentes e de extrema relevância social para Brasil. A psicologia social, especificamente, a TRS ainda tem muito a contribuir para uma análise crítica sobre o tema. Afinal, estamos diante de um campo que tem ganhando novos desdobramentos a cada dia, principalmente, com o crescimento de uma onda conservadora no país. 
Nos trabalhos descritos nessa revisão, a TRS assumiu a função de compreender as representações e crenças a respeito da homossexualidade e da homofobia. Com o objetivo central de compreender as expressões preconceituosas e como/onde elas se ancoram. Ademais, foi utilizada como produto (variável dependente) e, como processo e produto (variável independente) nos estudos. Dentre as funções que as representações sociais possuem, a função justificadora foi a mais utilizada.

Todos os trabalhos utilizaram dados provocados, seja por meio de entrevistas, escalas ou questionários. Outros tipos de dados, sem interferência do pesquisador, ainda não foram propostos, como exemplo, podemos citar a análise em diferentes mídias (jornais, chats, blogger, redes sociais, tirinhas, peças publicitárias, etc.). Esse questionamento surge porque em alguns casos os sujeitos podem controlar suas respostas para que se posicionem de forma socialmente desejável, já nessas outras plataformas a informação já está posta e o pesquisador apenas irá analisar, não interferindo no modo de produção das observações.

O presente trabalho possui suas limitações. Dissertações, teses e artigos indexados em periódicos interdisciplinares ou em outras áreas, por exemplo, não foram inseridos. Outras teorias da psicologia social também não foram contempladas nessa revisão. A utilização do termo "LGBTfobia" também não foi incluso nos critérios de busca, negligenciando possíveis artigos sobre 0 preconceito contra bissexuais, travestis, transexuais e transgêneros, por exemplo. Por isso, é importante que novas pesquisas e artigos, incluindo esse, sejam cada vez mais produzidos. Levando em consideração, principalmente, o lugar de falar dos LGBT, além de uma melhor articulação entre teorias para que os estudos sobre o tema avancem e contribuam para a erradicação, diminuição e auxílio na formação de política anti-homofobia. De toda forma, os resultados nos ofereceram informações importantes do panorama de uma abordagem específica que tem servido como base para muitos estudos da área. $\mathrm{A}$ homofobia é um fenômeno que, além de causar dor e sofrimento para os sujeitos de forma particular, se perpetuada em esfera institucional pode gerar consequências e retrocessos para toda a sociedade.

\section{Referências}

Abric, J. C. (1994). "Représentations sociales: aspects théoriques". In J. C. Abric (Org.), Pratiques sociales et representations (pp. 1136). Paris: PUF.

Apostolidis, T. (2006). Représentations sociales et triangulation: Une application en psychologie sociale de la santé. Psicologia: Teoria 
e pesquisa, 22(2), 211-226. doi:10.1590/S01023772200600020001

Araújo, L. F., Oliveira, J. S. C., Sousa, V. C., \& Castanha, A. R. (2007). Adoção de crianças por casais homoafetivos: um estudo comparativo entre universitários de direito e de psicologia. Psicologia \& Sociedade, 19(2), 95-102. doi:10.1590/S010271822007000200013

Borrillo, D. (2009). Homofobia. In T. Lionço, \& D. Diniz (Orgs.), Homofobia e educação: Um desafio ao silêncio (pp. 15-46). Brasília: Letras livres.

Camino, L., \& Pereira, C. (2000). O papel da psicologia na construção dos direitos humanos: Análise das teorias e práticas psicológicas na discriminação ao homossexualismo. Revista Perfil, 13(13), 49-69.

Cecílio, M. S., Scorsolini-Comin, F., \& Santos, M. A. (2013). Produção científica sobre adoção por casais homossexuais no contexto brasileiro. Estudos de Psicologia, 18(3), 507-516. doi:10.1590/S1413-294X2013000300011

Costa, A. B., \& Nardi, H. C. (2015). Homofobia e preconceito contra diversidade sexual: Debate conceitual. Temas em psicologia, 23(3), 715-726. doi:10.9788/TP2015.3-15

Doise, W. (2002). Da psicologia social à psicologia societal. Psicologia: teoria e pesquisa, 18(1), 27-35. doi:10.1590/S0102-37722002000100004

Fleury, A. R. D., \& Torres, A. R. R. (2007). Análise psicossocial do preconceito contra homossexuais. Estudos de Psicologia (Campinas), 24(4), 475-486. doi:10.1590/S0103$166 \times 2007000400007$

Gato, J., Carneiro, N. S., \& Fontaine, A. M. (2011). Contributo para uma revisitação histórica e crítica do preconceito contra as pessoas não heterossexuais. Crítica e Sociedade: Revista de cultura política, 1(1), 139-167. Recuperado de http://www.seer.ufu.br/index.php/criticasociedade/article/view/ $12542 / 7715$

Gouveia, R. C., Camino, L., Ribeiro, J. C., \& Souza, F. (2016). A influência das representações sobre os nordestinos nas relações intergrupais entre usuários de uma rede social digital. In M. E. O. Lima, A. R. R. Torres, \& E. M. Techio (Orgs.), Identidade nacional e representações do Brasil: abordagens integrativas (pp. 177-214). São Paulo: Scortecci.

Herek, G. M. (2000). The psychology of sexual prejudice. Current directions in psychological science, 9(1), 19-22. doi:10.1111/1467-8721.00051

Hudson, W. W., \& Ricketts, W. A. (1980). A strategy for the measurement of homophobia. Journal of Homosexuality, 5(4), 357-372. doi:10.1300/J082v05n04_02 
Jodelet, D. (2001). Representações sociais: Um domínio em expansão. In D. Jodelet (Org.), As representações sociais (pp. 17-44). Rio de Janeiro: EdUerj.

Jodelet, D. (2005). Loucuras e representações sociais. Petrópolis: Vozes.

Jodelet, D. (2011). Ponto de vista: Sobre o movimento das representações sociais na comunidade científica brasileira. Temas em Psicologia, 19(1), 19-26. Recuperado de http://pepsic.bvsalud.org/scielo.php?script=sci_arttext\&pid=S1 413-389X2011000100003

Jodelet, Denise. (2016). A representação: Noção transversal, ferramenta da transdisciplinaridade. Cadernos de Pesquisa, 46(162), 1258-1271. doi: 10.1590/198053143845

Junqueira, R. D. (2012). Homofobia: Limites e possibilidades de um conceito em meio a disputas. Bagoas-Estudos gays: Gêneros e sexualidades, 1(1), 1-22. Recuperado de https://periodicos.ufrn.br/bagoas/article/view/2256

Lacerda, M., Pereira, C., \& Camino, L. (2002). Um estudo sobre as formas de preconceito contra homossexuais na perspectiva das representações sociais. Psicologia: Reflexão e Crítica, 15(1), 165-178. doi:10.1590/S0102-79722002000100018

Lima, M. E. O., \& Techio, E. M. (2013). Academic training in social psychology in Brazil and South America. Estudos de Psicologia (Natal), 18(1), 75-82. Recuperado de http://www.scielo.br/pdf/epsic/v18n1/13.pdf

Logan, C. R. (1996). Homophobia? No, homoprejudice. Journal of homosexuality, 31(3), 31-53. doi:10.1300/J082v31n03_03

Morin, S. F. (1977). Heterosexual bias in psychological research on lesbianism and male homosexuality. American Psychologist, 32(8), 629-637. doi:10.1037//0003-066X.32.8.629

Moscovici, S. (2009). Representações sociais: Investigações em psicologia social. In S. Moscovici (Org.), Representações sociais: Investigações em psicologia social. Petrópolis: Vozes.

Neves, A. L. M, Sadala, K. Y., Silva, L. R., Teixeira, E., Ferreira, D. S., \& Silva, F. A. (2015). Representações sociais de professores sobre diversidade sexual em uma escola paraense. Psicologia Escolar e Educacional, 19(2), 261-270. doi:10.1590/21753539/2015/0192831

Pereira, A. D. S. L. S., Dia, S. M. P. D. S., Lima, T. J. S. D., \& Souza, L. E. C. D. (2017). As Crenças sobre a homossexualidade e o preconceito contra homossexuais no ambiente de trabalho. Temas em Psicologia, 25(2), 563-575. doi:10.9788/TP2017.210

Pereira, C. R., Torres, A. R. R., Falcão, L., \& Pereira, A. S. (2013). O papel de representações sociais sobre a natureza da homossexualidade na oposição ao casamento civil e à adoção 
por famílias homoafetivas. Psicologia: Teoria e Pesquisa, 29(1), 79-89. doi:10.1590/S0102-37722013000100010

Pereira, C. R., Torres, A. R. R., Pereira, A., \& Falcão, L. C. (2011). Preconceito contra homossexuais e representações sociais da homossexualidade em seminaristas católicos e evangélicos. Psicologia: Teoria e Pesquisa, 27(1), 73-82. doi:10.1590/S0102-37722011000100010

Pereira, D. F. (2017). Homossexualidade em cena: Da naturalidade ao preconceito revisitando a produção científica nacional. Itinerarius Reflectionis, 13(2), 1-19. doi:10.5216/rir.v13i2.41309

Peroni, R. O. (2011). Homofobia no Brasil: Uma revisão sistemática. Porto Alegre: UFRGS.

Reis, S. L. A, \& Bellini, M. (2011). Representações sociais: teoria, procedimentos metodológicos e educação ambiental. Acta Scientiarum - Human and Social Sciences, 33(2). 149-159. doi: 10.4025/actascihumansoc.v33i2.10256

Rodrigues, V., \& Boeckel, M. (2016). Conjugalidade e homossexualidade: Uma revisão sistemática de literatura. Nova Perspectiva Sistêmica, 25(55), 96-109. Recuperado de http://www.revistanps.com.br/nps/article/view/138

Sacco, A. M., Couto, M. C. P., \& Koller, S. H. (2016). Revisão sistemática de estudos da psicologia brasileira sobre preconceito racial. Temas em Psicologia, 24(1), 233-250. doi: 10.9788/TP2016.1-16

Santos, M. D. F. D. S., Andrade, D. A. D., Morais, E. R. C. D., Félix, L. B., Neto, A., Lima, M., \& Sousa, Y. S. O. (2013). An overview on Social Psychology in Brazil: Theoretical contributions from the production of journals. Estudos de Psicologia (Natal), 18(1), 17-23.

Recuperado http://www.scielo.br/pdf/epsic/v18n1/05.pdf

Scardua, A., \& Souza, E. A. D., Filho (2006). O debate sobre a homossexualidade mediado por representações sociais: Perspectivas homossexuais e heterossexuais. Psicologia: Reflexão e crítica, 19(3), 482-490. doi:10.1590/S010279722006000300017

Souza, E. D. J., Silva, J. P. D., \& Santos, C. (2015). Homofobia na escola: As representações de educadores/as. Temas em Psicologia, 23(3), 635-647. doi:10.9788/TP2015.3-09

Vignaux, G., \& Moscovici, S. (1994). Le concept de Themata. In C. Guimelli (Ed.), Structures et transformations des représentations sociales (pp. 25-72). Neuchâtel: Delachaux et Niestle.

Weinberg, G. H. (1972). Society and the healthy homosexual. London: Macmillan. 


\section{Endereço para correspondência}

\section{Lawerton Braga da Silva}

Avenida Antônio Lira, 507, casa 01, CEP 58039-050, João Pessoa - PB, Brasil

Endereço eletrônico: lawertonbraga@hotmail.com

\section{Renata Lira dos Santos Aléssio}

Centro de Filosofia e Ciências Humanas - Programa de Pós-graduação em Psicologia Departamento de Psicologia

Avenida da Arquitetura, s/n, 90 Andar, Cidade Universitária, CEP 50740-550, Recife - PE, Brasil

Endereço eletrônico: renatalir@gmail.com

Recebido em: 11/09/2018

Reformulado em: 11/03/2019

Aceito em: 20/03/2019

\section{Notas}

* Doutorando em Psicologia Social.

** Professora Adjunta e Doutora em Psicologia.

Financiamento: Capes - Coordenação de Aperfeiçoamento de Pessoal de Nível Superior

Este artigo de revista Estudos e Pesquisas em Psicologia é licenciado sob uma Licença Creative Commons Atribuição-Não Comercial 3.0 Não Adaptada. 